\title{
PENGARUH PENGUATAN OTOT RECTUS ABDOMINIS TERHADAP PENURUNAN TFU PADA IBU POSTPARTUM PERVAGINAM DI PMB KABUPATEN SLEMAN
}

\author{
THE EFFECT OF ABDOMINICAL RECTUS MUSCLE TOWARDS ON DECREASE OF \\ TFU IN POSTPARTUM PERVAGINAM MOTHER \\ IN PMB, SLEMAN DISTRICT
}

\section{Enny Fitriahadi ${ }^{1}$, Istri Utami ${ }^{2}$}

Program Studi Kebidanan Program Sarjana Terapan

Universitas 'Aisyiyah Yogyakarta Indonesia

Email : ennyfitriahadi@rocketmail.com

\begin{abstract}
ABSTRAK
Komplikasi yang terjadi pada masa nifas biasanya mengalami perdarahan, sub involusio uteri, payudara bengkak, putting susu lecet dll. Dengan penanganan dan pengawasan yang benar dan tepat komplikasi selama masa nifas akan menurun sehingga angka kesakitan dan kematian pada ibu akan menurun. Penelitian ini bertujuan untuk mengetahui pengaruh penguatan otot rectus abdominis terhadap penurunan tinggi fundus uteri pada ibu postpartum pervaginam di PMB Kabupaten Sleman. Tujuan dari penelitian ini adalah mengetahui penurunan tinggi fundus uteri (TFU) sebelum dan sesudah dilakukan intervensi penguatan otot rectus abdominis. Sampel dalam penelitian ini berjumlah 15 responden intervensi dan 15 responden dengan kelompok kontrol. Metode penelitian ini menggunakan quasi experimental dengan non-randomized pretest-posttes group design. Teknik pengambilan sampel menggunakan total sampling. Uji beda hasil pre test dan post test pada kelompok eksperimen atau non eksperimen menggunkan Wilcoxon dan Mann Whitney. Hasil penelitian ini didapatkan bahwa mayoritas penurunan TFU pada kelompok intervensi adalah cepat 10 (66.6\%) sedangkan pada kelompok kontrol penurunan TFU lambat 9 (60\%), dan berdasarkan hasil analisis bivariat didapatkan nilai p-value 0,003 yang artinya ada pengaruh penguatan otot rectus abdominis terhadap penurunan TFU ibu postpartum.
\end{abstract}

Kata kunci : penguatan otot rectus abdominis, TFU

\section{ABSTRACT}

Complications that occur during childbirth usually experience bleeding, sub involusio uteri, swollen breast, nipple blisters etc. By handling and supervising the correct and precise complications during the puerperium will decrease so that morbidity and mortality in the mother will decrease. This study aims to determine the effect of rectus abdominis muscle strengthening on the decrease in uterine fundus height in vaginal postpartum mothers in BPM Sleman District. The purpose of this research is to know the decrease of fundus uteri level (TFU) before and after intervention of rectus abdominis muscle strengthening. The sample in this study amounted to 15 respondents and 15 respondents with the control group. This research method uses quasi experimental with non-randomized pretest-posttes group design. The sampling technique uses total sampling. Different test results of pre test and post test in experimental or non experimental group using Wilcoxon and Mann Whitney. The result of this research shows that the majority of TFU decrease in intervention group is fast 10 (66.6\%) while in the control group decrease TFU is slow 9 (60\%), and based on bivariate analysis results obtained p-value 0,003 which means there is influence of rectus abdominis to decreased TFU of postpartum mother.

Keywords: muscle strengthening rectus abdominis, TFU 


\section{PENDAHULUAN}

Puerpurium (nifas) berlangsung selama 6 minggu atau 42 hari, merupakan waktu yang diperlukan untuk pulihnya alat kandungan pada keadaan yang normal (Ambarwati dan Wulandari, 2010).

Selama masa nifas tersebut berlangsung, ibu akan mengalami banyak perubahan, baik secara fisiologis maupun psikologis. Perubahan psikologis lebih banyak disebabkan karena perubahan peran barunya yaitu peran menjadi seorang ibu. Sedangkan perubahan fisiologis yang terjadi pada masa nifas merupakan proses pengembalian fisik ibu seperti keadaan semula sebelum hamil. Perubahan tersebut meliputi: perubahan sistem reproduksi, sistem pencernaan, sistem perkemihan, sistem muskuloskeletal, sistem endokrin, tanda vital, sistem kardiovaskuler, dan perubahan sistem hematologi. (Sulistyawati, 2009).

Salah satu perubahan fisiologis masa nifas adalah perubahan sistem reproduksi dimana meliputi perubahan corpus uterin, cervix, vulva dan vagina, serta otot-otot pendukung pelvis. Kemudian perubahan pada corpus uterin salah satunya adalah involusi uterus yaitu pemulihan uterus pada ukuran dan kondisi normal setelah kelahiran bayi yang diketahui sebagai involusi (Cunningham, 2013).

Involusi uterus dimulai setelah persalinan yaitu setelah plasenta dilahirkan, dimana proses involusi uterus berlangsung kira-kira selama 6 minggu. Involusi uteri pada ibu postpartum harus berjalan dengan baik, karena jika proses involusi

tidak berjalan dengan baik dapatmberakibat buruk pada ibu nifas seperti terjadi subinvolusi uteri yang dapat mengakibatkan perdarahan, selain itu adalah hiperinvolusi uteri, kelainan fisik lain adalah pemisahan otot perut atau yang biasa disebut dengan diastasis rectus abdominis (Ambarwati dan Wulandari, 2010).

Kontraksi otot perut akan membantu proses involusi yang dimulai setelah plasenta keluar segera setelah melahirkan. Ambulasi secepat mungkin dengan frekuensi sering sangat diperlukan dalam proses involusi. Kelancaran proses involusi dapat dideteksi dengan pemeriksaan lochea, konsistensi uterus, dan pengukuran tinggi fundus uteri (William dan Wilkins, 2012).

Keuntungan atau manfaat yang dapat diperoleh karena proses pemulihan fisik yang cepat dan baik bagi ibu adalah perasaan yang lebih baik, lebih sehat, lebih kuat, dan memungkinkan untuk dapat segera merawat dan membesarkan bayinya. Keuntungan bagi bayi adalah mendapatkan perawatan yang lebih baik dan kebutuhan yang dapat diperoleh dari ibu dapat terpenuhi (Ambarwati, 2008).

Menurut Brayshaw (2008) faktorfaktor yang menyebabkan percepatan involusi uterus (penurunan tinggi fundus uteri) salah satunya yaitu kontraksi. Kontraksi dapat ditimbulkan dari tekanan intra abdomen atau kekuatan otot abdomen yang baik. Latihan penguatan otot rectus abdominis merupakan suatu latihan dengan memberikan stimulus pada bagian muscullus rectus abdominis dengan mengontraksikan otot-otot tersebut sehingga dapat meningkatkan tekanan intra abdomen. Manfaat dilakukanya penguatan otot rectus abdominis adalah mengencangkan dinding rahim, mempercepat involusi uteri dan memperlancar pengeluaran lochea dan menurunkan tinggi fundus uteri dengan cepat. 
Latihan yang dilakukan pada otototot tertentu akan memberi efek yaitu aliran darah otot meningkat sehingga pengangkutan oksigen dan nutrisi lain untuk otot juga meningkat, hal ini akan memberikan kekuatan pada otot secara maksimal.

Proses involusi uteri berhubungan dengan penurunan tinggi fundus uteri karena salah satu indikator dalam proses involusi adalah tinggi fundus uteri. Salah satu cara untuk memperlancar proses involusi uteri adalah dengan melakukan penguatan otot abdomen khususnya musculus rectus abdominis.

Pengencangan otot abdomen merupakan latihan yang dilakukan oleh ibu nifas untuk menjaga otot abdominal agar menjadi lebih kuat setelah melewati proses persalinan (Brayshaw, 2008).

Bidan Praktek Mandiri di kabupaten Sleman sendiri masih banyak yang memberikan pelayanan kesehatan pada ibu nifas tetapi asuhan kebidanan yang diberikan masih bersifat sesuai dengan prosedur yang biasanya dilakukan belum pernah ada yang memberikan asuhan kebidanan terkait dengan penguatan otot rectus abdominis terhadap penurunan tinggi fundus uteri.

\section{METODE PENELITIAN}

Penelitian ini adalah quasi eksperimen (quasi experimental) dan mengukur pengaruh penguatan otot rectus abdominis terhadap penurunan tinggi fundus uteri pada ibu postpartum pervaginam. Penelitian ini membandingkan antara kelompok yang diberikan perlakuan (kelompok intervensi) dengan yang diberi tidak diberikan perlakuan (kelompok non intervensi). Design yang digunakan adalah non-randomized pretest-posttes group (Subaris, 2012).
Jumlah sampel dalam penelitian 30 responden dengan pembagian 15 responden pada kelompok eksperimen dan 15 pada kelompok non eksperimen.

Teknik pengambilan sampel adalah total sampling yaitu cara pengambilan sampel dengan mengambil seluruh jumlah populasi (Sugiyono, 2010).

Uji statistik yang akan digunakan untuk mengetahui perbedaan hasil pre test dan post test pada kelompok eksperimen atau non eksperimen menggunkan Wilcoxon dan untuk mengetahui perbedaan pre test dan post test pada 2 kelompok yang berbeda metode yang digunakan adalah Mann Whitney (Dahlan, 2013).

\section{HASIL DAN PEMBAHASAN}

a. Karakteristik Responden Identifikasi responden berdasarkan paritas, umur ibu, pendidikan dan pekerjaan pada kelompok intervensi dan kelompok kontrol pada tabel berikut ini :

Tabel 1 Distribusi Frekuensi Karakteristik

Responden Berdasarkan paritas, umur ibu, pendidikan dan pekerjaan pada kelompok intervensi dan kelompok kontrol

\begin{tabular}{|c|c|c|c|c|}
\hline \multirow[t]{2}{*}{$\begin{array}{l}\text { Karakteristik } \\
\text { Responden }\end{array}$} & \multicolumn{2}{|c|}{$\begin{array}{l}\text { Kelompok } \\
\text { Intervensi }\end{array}$} & \multicolumn{2}{|c|}{$\begin{array}{c}\text { Kelompok } \\
\text { Kontrol }\end{array}$} \\
\hline & $\mathrm{F}$ & $\%$ & $\mathrm{~F}$ & $\%$ \\
\hline \multicolumn{5}{|l|}{ Paritas } \\
\hline Primigravida & 5 & 33.3 & 5 & 33.3 \\
\hline Multigravida & 10 & 66.7 & 10 & 66.7 \\
\hline \multicolumn{5}{|l|}{ Umur Ibu } \\
\hline $\begin{array}{l}\text { Tidak } \\
\text { Reproduksi }\end{array}$ & 2 & 13.3 & 4 & 26.7 \\
\hline Reproduksi & 13 & 86.7 & 11 & 73.3 \\
\hline \multicolumn{5}{|l|}{ Pendidikan } \\
\hline Menengah & 13 & 86.7 & 14 & 93.3 \\
\hline $\begin{array}{l}\text { Perguruan } \\
\text { Tinggi }\end{array}$ & 2 & 13.3 & 1 & 6.7 \\
\hline \multicolumn{5}{|l|}{ Pekerjaan } \\
\hline $\begin{array}{l}\text { Tidak } \\
\text { Bekerja }\end{array}$ & 10 & 66.7 & 10 & 66.7 \\
\hline Bekerja & 5 & 33.3 & 5 & 33.3 \\
\hline
\end{tabular}

Sumber : Data Primer, 2018 
Dari tabel 1 dapat diketahui bahwa karkteristik kedua kelompok meliputi : Paritas pada kelompok intervensi dan kontrol mayoritas adalah multigravida 10 (66.7\%), umur ibu pada kelompok intervensi mayoritas umur reproduksi $13 \quad(86.7 \%)$ dan pada kelompok kontrol umur ibu mayoritas adalah umur reproduksi 11 (73.3\%), pendidikan ibu pada kelompok intervensi mayoritas adalah pendidikan menengah $13(86.7 \%)$ dan pada kelompok kontrol mayoritas berpendidikan menengah 14 (93.3\%), pekerjaan ibu mayoritas adalah tidak bekerja baik kelompok intervensi maupun kontrol 10 (66.7\%).

b. Analisis Univariat

1) Kelompok Intervensi

\begin{tabular}{lccr}
$\begin{array}{l}\text { Tabel 2 } \\
\text { dilakukan } \\
\text { dilakukan } \\
\text { Intervensi }\end{array}$ & $\begin{array}{c}\text { Distribusi } \\
\text { Intervensi } \\
\text { Intervensi }\end{array}$ & $\begin{array}{c}\text { TFU } \\
\text { dan } \\
\text { pada }\end{array}$ & $\begin{array}{r}\text { sebelum } \\
\text { sesudah } \\
\text { Kelompok }\end{array}$ \\
\hline $\begin{array}{c}\text { Penurunan } \\
\text { Tinggi }\end{array}$ & $\mathrm{f}$ & $\%$ \\
$\begin{array}{l}\text { Fundus Uteri } \\
\text { Lambat }\end{array}$ & 5 & 33,3 \\
Cepat & 10 & 66,6 \\
\hline Jumlah & 15 & 100,0 \\
\hline
\end{tabular}

Berdasarkan tabel 2 mayoritas penurunan tinggi fundus uteri pada kelompok intervensi penurunannya cepat $10(66,6 \%)$.

2) Kelompok Kontrol

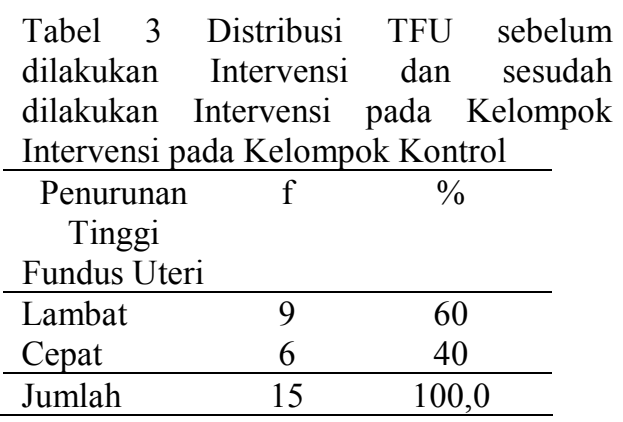

Berdasarkan tabel 3 penurunan tinggi fundus uteri pada kelompok kontrol mayoritas penurunannya lambat $9(60 \%)$.

\section{a. Analisis Bivariat}

Tabel 4 Distribusi Frekuensi Penguatan Otot Rectus Abdominis terhadap Penurunan TFU pada Ibu Postpartum pada Kelompok Intervensi

\begin{tabular}{|c|c|c|c|c|c|c|}
\hline & $\mathrm{N}$ & Mean & $\begin{array}{c}\text { Std. } \\
\text { Deviatio } \\
\mathrm{n} \\
\end{array}$ & $\begin{array}{l}\text { Mini } \\
\text { mum }\end{array}$ & $\begin{array}{l}\text { Maxi } \\
\text { mum }\end{array}$ & $\begin{array}{l}\text { Sig (2- } \\
\text { tailed) }\end{array}$ \\
\hline $\begin{array}{l}\text { TFU } \\
\text { sebelum }\end{array}$ & 15 & 1.60 & .507 & 1 & 2 & .003 \\
\hline $\begin{array}{l}\text { TFU } \\
\text { sesudah }\end{array}$ & 15 & 2.20 & .561 & 1 & 3 & \\
\hline
\end{tabular}

Berdasarkan tabel 4 hasil analisis pada kelompok intervensi dinyatakan bahwa nilai Signifikansi: 0,003 maka Ho di tolak Ha diterima artinya ada pengaruh penguatan otot rectus abdominis terhadap penurunan TFU.

Dari hasil analisis data didapatkan hasil mayoritas tinggi fundus uteri (TFU) pada ibu nifas sebelum diberikan intervensi mengalami penurunan TFU dan setelah diberikan intervensi penguatan otot rectus abdominis TFU ibu nifas mengalami penurunan TFU yang signifikan atau cepat $10(66,6 \%)$. Dari data diatas dapat dianalisis bahwa penguatan otot rectus abdominis sangat efektif terhadap penurunan TFU pada ibu nifas. Hasil uji statistik didapatkan nilai p-value adalah 0,003. Hal ini sesuai dengan tujuan penelitian ini yaitu penguatan otot rectus abdominis bermanfaat bagi ibu nifas khususnya penurunan TFU selama masa nifas.

Responden dalam penelitian ini adalah ibu nifas 2 jam postpartum dimana setelah plasenta lahir kondisi uterus normal berukuran 3 jari dibawah pusat, perubahan ini lah yang menjadi perhatian 
pada tenaga kesehatan khususnya bidan dan dokter kebidanan untuk segera memulihkan dan mengembalikan alat-alat reproduksi ibu selama masa nifas.

Selama masa nifas ibu dalam kondisi mengalami perubahan sehingga pemulihan kembali alat reproduksi sangat di perhatikan, bidan dalam memberikan asuhan pelayanan kebidanan secara evidance based yaitu mengurangi rasa nyeri atau sakit pada ibu nifas dengan melakukan latihan-latihan yang dapat memulihkan kondisi fisik dan psikis ibu. Melalui latihan penguatan otot rectus abdominis inilah tinggi fundus uteri ibu dapat turun dengan perlahan, tetapi jika ibu nifas melakukannya dengan rutin dan teratur, penurunan TFU ini akan lebih cepat di banding yang tidak melakukan latihan.

Perubahan kedua selain penurunan TFU latihan penguatan rectus abdominis dapat mengembalikan kondisi uterus seperti sebelum hamil dan dapat juga mengencangkan perut terutama diastatis recti dextra dan sinistra. Hal tersebut dikarenakan tahap awal dari kerja fisik berat, satu bagian dari kemampuan energy aerobic dalam otot seseorang akan berkurang. Keadaan ini disebabkan oleh dua efek yaitu yang disebut dengan hutang oksigen dan pengurangan cadangan glikogen dari otot. Pada kerja otot yang berat hampir semua cadangan oksigen digunakan untuk metabolism aerob sehingga setelah kerja otot selesai cadangan oksigen harus segera digantikan. Sedangkan pemulihan cadangan glikogen otot membutuhkan waktu yang lebih lama karena hal ini dipengaruhi oleh kebiasaan diet sebelum dan sesudahnya (Guyton, 2010).

Perubahan ketiga dengan melakukan latihan ini ibu dapat berlatih mobilisasi secara dini yang dapat membantu menurunkan Tinggi Fundus
Uteri secara bertahap. Dengan bergerak, hal ini akan mencegah kekakuan otot dan sendi sehingga juga mengurangi nyeri, menjamin kelancaran peredaran darah, memperbaiki pengaturan metabolisme tubuh, mengembalikan kerja fisiologis organ-organ vital yang pada akhirnya justru akan mempercepat penyembuhan luka (Prihartini, 2014).

Proses involusi uterus akan berjalan dengan lancar apabila dilakukan stimulus otot rectus abdominis yang berguna untuk melancarkan sirkulasi oksigen dalam darah dengan cara mengontaksikan dan meretraksikan otototot yang berada dalam uterus (Suryanti, 2016).

Menurut Ambarwati (2008) bahwasanya gangguan proses involusi dan pemisahan otot-otot perut (diastasis rectus abdominis) ini dapat menyebabkan perdarahan post partum. Kontraksi otototot perut akan membantu proses involusi yang dimulai setelah plasenta dilahirkan. Ambulasi secepat mungkin dengan frekuensi sering sangat diperlukan dalam proses involusi. Kelancaran proses involusi dapat dideteksi dengan pemeriksaan lochia, konsistensi uterus, dan pengukuran tinggi fundus uteri.

Berdasarkan hasil karakteristik ibu bahwa mayoritas paritas multigravida dimana ibu nifas yang multigravida lebih sering melakukan mobilitas dini dibanding dengan ibu yang primigravida. Pada ibu primigravida rata-rata masih merasakan nyeri pada luka bekas jahitan sehingga ibu masih merasa takut dan menunda untuk melakukan mobilisasi dini. Hal ini sejalan dengan penelitian Andriyani (2013) bahwa dengan melakukan senam nifas atau mobilisasi dini akan merangsang otot-otot polos untuk berkontraksi. Dampak yang terjadi apabila tidak melakukan mobilisasi dini diantaranya adalah varises, 
tromboplebitis vena yang disebabkan karena sumbatan vena oleh bekuan darah yang tidak lancar yang diakibatkan ibu membatasi gerakan selama masa nifas, infeksi karena involusi uterus yang tidak baik sehingga sisa darah tidak dapat dikeluarkan dan perdarahan menjadi abnormal. Dengan melakukan latihan dapat merangsang kontraksi uterus menjadi lebih baik sehingga menghindarkan resiko terjadinya perdarahan (Suherni, 2009).

Dilihat dari segi umur ibu mayoritas adalah berumur reproduksi dimana di umur tersebut adalah umur yang baik untuk bereproduksi, ibu yang berumur reproduksi diharapkan mampu untuk bisa melakukan latihan secara dini dan mandiri.

Berdasarkan pendidikan ibu mayoritas berpendidikan menengah dimana pada pendidikan tersebut ibu nifas mampu memahami arti pentingnya masa nifas, segala informasi terkait dalam masa nifas sudah diberikan ibu saat menjelang pulang dari rumah bersalin, informasi yang diberikan diantaranya konseling pemberian ASI eksklusif, perawatan bayi dan tidak lupa perawatan ibu saat nifas diantaranya adalah penguatan otot rectus abdominis.

Dilihat dari segi pekerjaan ibu mayoritas ibu rumah tangga seharusnya memungkinkan untuk melaksanakan latihan lebih aktif karena memiliki waktu luang yang lebih banyak dibanding dengan ibu nifas yang bekerja. Keberhasilan pelaksanaan latihan di dukung oleh kondisi ibu yang baik, kesadaran dan motivasi yang tinggi yang timbul dari klien sendiri untuk melakukan proses ini serta peran serta tenaga kesehatan untuk memberikan pendidikan kesehatan terkait mobilisasi dini atau latihan sejak dini (Andriyani, 2013).

\section{SIMPULAN}

Berdasarkan hasil penelitian pengaruh penguatan otot rectus abdominis terhadap penurunan TFU pada ibu postpartum pervaginam di BPM kabupaten Sleman dapat disimpulkan sebagai berikut :

a. Mayoritas penurunan TFU ibu nifas pada kelompok intervensi yaitu mengalami penurunan cepat $10(66,6$ $\%)$.

b. Mayoritas penurunan TFU ibu nifas pada kelompok kontrol yaitu mengalami penurunan lambat 9 $(60 \%)$.

c. Ada pengaruh penguatan otot rectus abdominis terhadap penurunan TFU ibu postpartum dengan nilai $\mathrm{p}$-value 0,003 .

\section{UCAPAN TERIMA KASIH}

Diberikan kepada Kementerian Riset, Teknologi dan Pendidikan Tinggi Republik Indonesia, selaku pemberi hibah penelitian dosen pemula.

\section{DAFTAR PUSTAKA}

Notoatmodjo. 2013. Metodologi Penelitian kesehatan. Jakarta: Rineka Cipta

Subaris,H. 2012. Teknik Sampling Untuk Penelitian Kesehatan. Yogyakarta:Graha Ilmu

Sugiyono. 2010. Statistika Untuk Penelitian. IKAPI. Jawa barat :CV Alfabeta

Prihartini. 2014. Pengaruh Mobilisasi Dini Terhadap Penurunan Tinggi Fundus Uteri Pada Ibu Nifas Di Paviliun Melati RSUD Jombang. Jurnal Edu Health, Vol. 4 No. 2, September 2014

Rahayu, D,P. 2015. Perbedaan Penurunan Tinggi Fundus Uteri Setelah Pemberian Jus Nanas Pada Ibu Post Partum Di Kabupaten Klaten. Jurnal Ilmiah Kebidanan 
Bidan Prada, Vol. 6 No. 1 Edisi Juni 2015, hlm. 108-115

Suryanti Dan Ambarwati. 2016. Manfaat Stimulus Vertebra Cervikalis Ke 5-6 Dan Stimulus Otot Rectus Abdominis Terhadap Perubahan TFU Ibu Post Partum Per Vaginam. Jurnal Kebidanan Universitas Muhammadiyah Semarang Vol 6 No 1 Februari 2017

Guyton, Arthur C. 2010. Buku Ajar Fisiologi Kedokteran. Jakarta : EGC

Bahiyatun. 2013. Buku Ajar Asuhan Kebidanan Nifas Normal. Jakarta : EGC

Ambarwati, E, \& Wulandari, D. 2010. Asuhan Kebidanan Nifas.Yogyakarta: Cendekia Press

Cunningham, F. Gerry. 2013. Obstetri William Vol. 1. Jakarta: EGC

Dahlan, S.M. 2013. Besar Sampel dan Cara Pengambilan Sampel. Jakarta : Salemba Medika.

Brayshaw, Eileen. 2008. Senam Hamil \& Nifas Pedoman Praktik Bidan. Jakarta:EGC

Williams \& Wilkins. 2012. Kapita Selekta Penyakit. Jakarta : EGC

Sulistyawati, Ari. 2009. Buku Ajar Asuhan Kebidanan pada ibu nifas. Yogjakarta: Andi Offset

Suherni; Widyasih H; Rahmawati A. 2009. Perawatan Masa Nifas. Jakarta : Fitramaya

Andriyani; Nurlaila; Pranajaya. 2013. Pengaruh Senam Nifas Terhadap Penurunan Tinggi Fundus Uteri Pada Ibu Postpartum. Jurnal Keperawatan Volume IX, No 2, Oktober 2013 